\title{
Das tensões ao Desejo: Traços do trovadorismo em Sonhei-Te, de Gilka Machado
}

\author{
Luiz Felipe Verçosa da SILVA ${ }^{1}$ \\ (Universidade Estadual de Alagoas - UNEAL)
}

Resumo - A fluminense Gilka Machado (1893-1980) foi uma das pioneiras no processo de reconhecimento de uma identidade feminina dentro das produções literárias brasileiras, uma vez que procurou bravamente, nos signos líricos, desnudar o corpo atuante da mulher em suas configurações mais internas, considerando as contorções do sentimento feminino como marca de diferença da palavra poética e da voz que fala a partir de um corpo desejante, traduzido por inquietações da libido feminina que rompe com os paradigmas impostos socialmente à mulher. Construção crítica presente em toda obra da autora, como evidenciado no livro Mulher Nua (1922), em que surge a itinerância do desejo. Partindo dessa discussão, procurase investigar por meio do método comparativo, como traços estéticos da Literatura Portuguesa, em especial do período literário do Trovadorismo, estão presentes na poesia de Gilka Machado, no que diz respeito às sugestões sentimentais do poema Sonhei-te, presente na antologia Os mais belos sonetos que o amor inspirou (1963), organizada pelo poeta acreano J.G. de Araujo Jorge. Para a ambientação dessas abordagens e subsídios que ratifiquem os objetivos e os possíveis resultados obtidos no respectivo trabalho, fundamentarse-á as pesquisas com as contribuições científicas de Moisés (2013), Bosi (1977), Gonçalves (2012), Cara (1989) e Carvalhal (2006).

Palavras-chave: Literatura Portuguesa; Literatura Brasileira; Gilka Machado.

\begin{abstract}
Fluminense Gilka Machado (1893-1980) was one of the pioneers in the process of recognizing a female identity within Brazilian literary productions, since she bravely sought, in lyrical signs, to bare the active body of women in their most internal configurations, considering the contortions of the female feeling as a mark of difference in the poetic word and the voice that speaks from a desiring body, translated by concerns about the female libido that breaks with the paradigms socially imposed on women. Critical construction present in every work of the author, as evidenced in the book Mulher Nua (1922), in which the itinerancy of desire appears. Based on this discussion, we seek to investigate through the comparative method, as aesthetic features of Portuguese Literature, especially from the literary period of Troubadour, are present in the poetry of Gilka Machado, with regard to the sentimental suggestions of the poem Sonhei-te, present in the anthology The most beautiful sonnets that love inspired (1963), organized by the Acre poet JG de Araujo Jorge. For the setting of these approaches and subsidies that ratify the objectives and the possible results obtained in the respective work, the research with the scientific contributions of Moisés (2013), Bosi (1977), Gonçalves (2012), Cara (1989) will be based ) and Carvalhal (2006).

\footnotetext{
${ }^{1}$ Graduado em Letras - Português pela Universidade Estadual de Alagoas - UNEAL, Campus IV - São Miguel dos Campos. Membro do Grupo de Estudos em Literatura Comparada - GELIC da Universidade Federal da Paraíba. E-mail para contato: felipevercosa@ outlook.com.
} 
Keywords: Portuguese Literature; Brazilian literature; Gilka Machado

\section{Introdução}

O Trovadorismo (1198-1418) se caracterizou como o primeiro movimento literário da Língua Portuguesa, surgido no final do século XII e que teve o seu apogeu no final século XIV. De cunho originalmente provençal, a lírica trovadoresca, após se popularizar entre a sociedade nobre da época, propagou-se nas raízes dos subúrbios da antiga Galícia, atual Portugal, produzindo a partir daí mudanças significativas na sua composição artística e na cultura Lusitana.

Para Moises (2008), o Trovadorismo foi um movimento literário de caráter popular, sem relação com a cultura da antiguidade clássica greco-latina e voltado para o entretenimento. As suas liras representavam essa natureza popular e apegada às raízes do povo, pois sempre procuravam manifestar os sentimentos mais intensos e mais obscuros dos seres humanos, uma vez que o trovador utilizando o reduto artístico como escape existencial, vomitava da forma mais explícita possível o seu desdém a algo ou alguém. Essas produções eram chamadas segundo Massini-Cagliari (2007) no Cancioneiro Galego-Português, de Cantigas de Escárnio e Maldizer. E, quando reverberavam o seu amor consumado/platônico a alguma dama que tivera despertado os seus encantos, sempre munidos em suas declamações de instrumentos musicais que enriqueciam as suas mensagens poéticas, produziam as chamadas de Cantigas de Amor e Amigo, como informa Massini-Cagliari (2007).

Por esses fatores, o Trovadorismo foi um dos movimentos mais importantes da Literatura Universal, principalmente da Literatura Lusitana, e por meio dela influenciou o campo temático e estético da Literatura Brasileira, que herdou, além da vernácula portuguesa, as raízes dessas manifestações artísticas, como pode se notar na poesia de Cecilia Meireles ${ }^{2}$, que, ao se apropriar e ressignificar a identidade trovadoresca, compôs versos que dialogavam com as liras amorosas, trazendo a associação mágica, a consciência do eu lírico com a natureza, as repetições na composição poética que davam musicalidade pelo paralelismo, o

\footnotetext{
${ }^{2}$ Cecília Meireles (1901-1964) foi uma poetisa, professora, jornalista e pintora brasileira. Foi uma das primeiras vozes femininas de grande expressão na literatura brasileira, com mais de 50 obras publicadas. Com 18 anos estreia na literatura com o livro "Espectros".
} 
uso do refrão e a carga semântica de nostalgia que se perpetuava na voz lírica de seus poemas, indícios da busca por um amor ou uma tentativa frustrada perante desejos incompletos, sentimentalização característica da verve discursiva presente nas Cantigas de Amigo.

Então, levando em consideração essas raízes trovadorescas no cerne discursivo da Literatura Brasileira, principalmente na produção feminina, observa-se que nitidamente esses traços também estão caracterizados na construção amorosa do soneto Sonhei-te, da escritora fluminense Gilka Machado (1893-1980), uma das vozes mais autênticas/ousadas da Literatura Brasileira, que rompeu por meio de seu lirismo tocante e de introspecção erótica, com os mais perversos paradigmas e tabus da época, expressando as mais recônditas e singelas sensações que instauram a carne da mulher, que por viver amalgamada pelos (m)achismos da sociedade, vai se autodescobrindo como um pássaro recém liberto, provocando nela um puro estado de êxtase, que só pode ser traduzido pela e para a poesia, que detém de um mecanismo que potencializa os sentimentos mais abstratos e purifica o interdito, bem como aborda Silva (2018) ao explicar o processo de substantivação que a poesia exerce no ser humano, já que a poesia/literatura fora e é um instrumento fundamental para o processo de substantivação do eu enquanto ser racional, pois o dá a oportunidade de existir, resistir e imortalizar as suas indagações e vivências por meio da palavra.

Para Carvalhal (2006, p. 86) "a investigação de um mesmo problema em diferentes contextos literários permite que se ampliem os horizontes do conhecimento estético ao mesmo tempo em que, pela análise contrastiva, favorece a visão crítica das literaturas nacionais". Visto isso, o objeto desse trabalho visará por meio do método comparativo, mostrar como traços estéticos da Literatura Portuguesa, em especial do período literário do Trovadorismo (século XII até o século XIV) estão presentes na poética transgressora de Gilka Machado.

\section{A verve trovadoresca em sonhei-te}

Com um lirismo enrustido de tensão amorosa, Sonhei-te $e^{3}$ de Gilka Machado, um dos quatro sonetos publicados unicamente na Antologia Poética Os mais belos sonetos que o amor inspirou (ARAUJO, 1973), apresenta as lamúrias de um eu lírico, que de tão frustrado

\footnotetext{
${ }^{3} \mathrm{Na}$ Antologia Poética Os mais belos sonetos que o amor inspirou Vol. I (1963), de J.G. de Araujo Jorge, o poema Sonhei-te foi originalmente publicado com o título de Sôneto. Contudo nas reedições posteriores da Antologia Poética, o título foi mudado pelo autor para uma melhor caracterização do texto, pois já havia no livro outro poema de Gilka Machado com o mesmo título de Sôneto.
} 
com as suas idealizações amorosas, canta para o Amor a sua mais deliberada desilusão, navegando pelo vasto descobrimento do ser, que como em todas as instâncias da vida, precisa sofrer para entender as diretrizes de seus sentimentos.

$\mathrm{Na}$ representação consistente de um eu lírico saudosista, que sem recursos físicos para externar os seus sentimentos a algo/alguém que deveras é ou está distante, mas que ainda pulsa firme em sua memória busca refúgio na introspecção feminina, mediante as suas percepções de sentimentos do mundo e, a partir da sua poética, externa as suas inquietações sentimentais.

Moisés (2014, p.13) expõe que "dentro do trovadorismo português, o ponto mais alto do processo sentimental situava-se antes de a dama atender aos reclamos do apaixonado". Nisso percebe-se que o poema de Gilka dialoga com as Cantigas de Amor, já que o trovador centra-se na contemplação de um amor não realizado, colocado na promessa de um futuro. Nesse sentido, Sonhei-te conversa com a lírica de amor provençal, pois está sempre reclamando o amor no plano do sonho.

E essa é a essência da Antologia Os mais belos sonetos que o amor inspirou, organizada pelo também poeta J.G. de Araujo Jorge (1914-1987), que alimentada pelo desejo de tornar evidente as inúmeras consequências que o amor inspira no ser, reuniu 400 sonetos de 300 poetas brasileiros, na intenção de celebrar essas composições e mostrar a atemporalidade que esse sentimento causa no subconsciente literário coletivo. Como é visualizado em Sonhei-te e no decorrer dos demais sonetos do livro.

Em Sonhei-te, o eu lírico sempre remete a sua percepção a algo/alguém que está distante, vislumbrando com ânsia o seu ideal nesse algo/alguém, chegando apenas a se enxergar nesse amor, ao mesmo tempo em que paradoxalmente, o eu lírico tem consciência de que não terá mais esse amor. Após isso, abatido enfim por sua triste realidade, o eu lírico retorna ao seu mundo real pelo apoteótico regresso desse sentimento. Nisso, o eu lírico na consciência plena de suas fraquezas, foge para não se deixar levar pelos infortúnios desse amor, que assim como a vida tem início, meio e fim.

Esses conflitos emocionais são característicos das Cantigas de Amor, já que nelas, assim como observa Moisés (2013, p. 25) “os apelos amorosos ganham aura de transcendência: repassa-os um torturante sofrimento interior que se segue à certeza da inútil súplica e da espera dum bem que nunca chega ou parece impossível”. Nessa perspectiva, o amor torna-se um sentimento paradoxal e inconstante ao modo que o eu lírico, mesmo ciente 
da impossibilidade da contemplação plena desse sentimento, alimenta esperanças falsas naquilo que ele sabe que não existirá.

Características que também estão presentes nas perspectivas Renascentistas/Classicistas de Camões, que se pode estabelecer relação não só com traços pertinentes das liras trovadorescas, e sim, do próprio cerne literário, entendendo que como Gilka Machado foi, sobretudo, uma escritora Simbolista, recebeu influência das escolas clássicas, como a de Camões. O que deu a autora, uma possibilidade de ressignificação de suas percepções poéticas/sensórias por meio da incorporação das premissas desses movimentos literários portugueses.

Ainda nessa perspectiva, percebe-se como em Sonhei-te a ilustração dos sentimentos amorosos perpassam por várias sensações e revelam traços da própria psique do eu lírico, que movida por sentimentos de indecisão e insegurança, apresenta as faces de um amor mal resolvido e que deixou lacunas não preenchidas. Esse sentimento, quando volta, causa um choque de sensações aleatórias de amor e ódio dentro do psicológico do eu lírico, que desesperado para conter essas feridas reabertas, clama em misericórdia para estabelecer a sua harmonia, que foi danificada por esses sentimentos.

No poema, o argumento que se faz condizente se levarmos em consideração que a própria etimologia do significado da palavra sonhar, metaforicamente já remete a entregar-se a fantasias e devaneios, ficando evidente essa preocupação do eu lírico em relação a esse amor. Para explicar melhor esses conflitos oníricos, Freud explica que:

As emoções profundas da vida desperta, as questões e os problemas nos quais gastamos nossa principal energia mental voluntária não são os que se costumam apresentar de imediato à consciência onírica. No que tange ao passado imediato, são basicamente as impressões corriqueiras, casuais e "esquecidas" da vida diária que reaparecem em nossos sonhos. As atividades que estão mais intensamente despertas são aquelas que dormem mais profundamente. (FREUD, 2014, p. 27).

Com essas observações, pode-se ilustrar como a contextualização dos versos do poema revela os conflitos internos que agitam os estímulos sensoriais do eu lírico em Sonhei-te, apresentando a maneira pela qual esses sentimentos mal resolvidos, afetam o subconsciente desse ser, que deliberadamente pleno de suas limitações perante a esse submerso amor submisso, que em outrora fora tão idealizado que desconstruiu toda a percepção sentimental, luta para não se deixar levar pelo arrebatamento que essas sensações causam em si, numa 
ávida batalha do eu contra si mesmo. Nesse viés, Freud (2014) explica é consequência dos estímulos, desejos sexuais e aversões latentes que descansam no coração, que acionados, se combinam com outros desejos incubados e emergem em sonhos ou se fundem a outros sonhos já existentes, causando posteriormente esse conflito interno que se contextualiza e é verificado no decorrer da construção narrativa dos versos em Sonhei-te. O sonho, nesse caso, é a principal fraqueza que influencia e desencadeia esses sentimentos avulsos de bem me quer... mal me quer, o imã que reestabelece tudo aquilo pelo qual o fadado e tentado eu lírico, gostaria de esquecer de sua inconstante e irresponsável consciência.

Já a partir da estrutura do poema, pode-se também apresentar e estabelecer uma relação de proximidade com traços do Trovadorismo, pois como se trata de uma estrutura métrica similar à forma paralelística de se escrever utilizada pelos trovadores, extrai-se de cada verso de Sonhei-te o sofrimento do eu lírico, que precisou sistematizar em estrofes metricamente harmoniosas, os seus martírios.

Que como Moises (2008) aborda, segue uma ordem crescente, através das estrofes (cobra ou talho), que reforçada no estribilho ou refrão, onde o trovador pode rematar cada estrofe, reforçando a angustiante ideia fixa para a qual ele não encontra consolo. De acordo com Zilberman:

A obra literária não está voltada para dentro de si mesma. Seus componentes internos são comunicativos, como se observou no começo; além disso, eles interagem com ideias e valores experimentados pela sociedade em uma dada época. Assim, ela insere-se num contexto mais amplo, diante do qual assume sua existência particular. É seguidamente esse contexto com o qual a obra interage que determina seu caráter artístico, pois o contexto se relaciona com as normas estéticas vigentes. (ZILBERMAN, 2012, p. 84).

Ademais, a estética do poema Sonhei-te contribui para a gesticulação de que Gilka Machado absorveu de forma direta ou indireta, influências dos aspectos discursivos intrínsecos ao Trovadorismo, pois se trata de uma composição lírico amorosa, simular a estrutura das Cantiga de Amor, já que traz à luz em sua narrativa poética o lamento suplicante de um eu lírico, que expressa por meio de singelas preces o seu desdém, clamando para que esse amor, que em outrora causou uma falsa harmonia, não regresse e cause outra ilusão afetiva em seu coração já abalado. Mostra como a natureza da estrutura poética revela muito a respeito da própria gênese da escritora, pois "a mensagem poética embora possa conter um fato, busca ainda, acionar estados, vivências”. (CORTEZ E RODRIGUES, 2009, p. 56). 
Ainda pensando na estrutura do poema seguindo a perspectiva de Moisés (2008), algo chama atenção e dá margem para se observar que há além do que foi dito anteriormente, outras relações estruturais com as Cantigas de Amor, principalmente no que diz respeito ao número de estrofes distribuídas no poema, que se assemelham com as estruturas utilizadas no Trovadorismo, que normalmente possuíam três ou quatro estrofes, decassílabas, octossílabas ou com quatro ou três versos em cada estrofe, é igual à estruturação de Sonhei-te, pois se trata de um soneto.

Tendo distinção apenas na composição da voz lírica do texto, que nas Cantigas Trovadorescas de Amor eram quase sempre cantadas pelos homens, que tomando para si as dores que ele mesmo causou no coração da dama, trazia para as cantigas, o sentimento que a mulher tivera sentido em relação a tudo o que foi causado por ele. E mesmo que isso seja um traço característico das composições poéticas desse período literário, gera numa análise mais social e crítica a respeito da posição que mulher detinha nessa época, uma polêmica quanto à postura desse trovador, que mesmo sendo o causador de tantas desilusões afetivas, não tinha a percepção sentimental de projetar aquilo que não sentiu, e sim causou, mesmo que essa projeção poética seja carregada de uma culpa ou de um sentimento de arrependimento para com o que aconteceu.

Contudo, Sonhei-te traz uma ruptura com esse traço característico das Cantigas de Amor, passando definitiva e apropriadamente a voz à mulher que sofreu com os dissabores de um sentimento platônico, para que ela possa assim, expor as tensões que esse sentimento causou em seu coração, num movimento progressista que já dá uma nova roupagem a essas características trovadorescas, por meio da inserção da voz feminina para falar de si mesma.

E ao trazer essa leitura, é importante salientar que não está provado em nenhum registro bibliográfico ou digital, que Gilka Machado tinha consciência desse traço característico que as Cantigas de Amor apresentavam, nem tampouco a noção de que mesmo não direcionando uma postura machista e patriarcal, os trovadores se apropriavam do lugar de fala da mulher e as inibiam de expressar o seu sofrimento afetivo.

Mas, levando em consideração a posição progressista que Gilka assumiu durante toda a sua carreira literária, não é um equívoco levantar a hipótese de que mesmo de maneira inconsciente, a autora ressignificou os moldes poéticos de se construir os discursos e emancipou a sua voz feminina. A seguir apresentamos o poema para efeito de leitura e análise. 


\section{Sonhei-te}

\section{Gilka Machado (1893/1980)}

Sonhei-te tantos anos! Tantos anos! Eras o meu ideal de amor e de arte, buscava-te a toda hora e em toda parte nessa ânsia inexplicável dos insanos.

Enfim, vencida pelos desenganos, como quem nada espera que lhe farte a alma faminta, exausta de sonhar-te, abandonei-me do destino aos danos.

Surges-me agora, em meio da jornada da Vida: vens do Inferno ou vens da Altura?

- Não sei: mas de ti fujo, apavorada!

E, em lágrimas, minha alma conjetura:

uma felicidade retardada

quase sempre se torna desventura.

(In: Os mais belos sonetos que o amor inspirou, 1963, p. 172).

Outro ponto de bastante relevância na construção do poema, diz respeito à própria métrica do texto, que além de se distribuir em uma composição de soneto, está organizada com uma cavalgamento bastante interligado sintática e semanticamente, com rimas que são interpoladas nas duas primeiras estrofes $\left(1^{\circ}-\mathrm{ABBA}, 2^{\circ}-\mathrm{BAAB}\right)$ e alternadas nas duas ultimas estrofes $\left(3^{\circ}-\mathrm{CDC}\right.$ e $\left.4^{\circ}-\mathrm{DCD}\right)$, que imbricadas com a utilização de metáforas e aliterações revelam como a autora utiliza essas estruturas e recursos da linguagem para atingir um ritmo que contagie e desperte o sentido no leitor. Objetivando fazer com que este leia o poema com os olhos e os ouvidos, isto é, como uma organização visual e sonora. (GOLDSTEIN, 1985, cp. 2).

Do mesmo modo que eram desenvolvidas as Cantigas Trovadorescas do século XII, quando os trovadores se apropriavam desses mesmos recursos sonoros da linguagem para elucidar a sua mensagem, que ganhava mais proporção pelo auxílio de instrumentos musicais; como alaúdes, harpas e cítaras, para fazer com que leitor se transfigurasse sinestesicamente para dentro de suas canções. Como se observa na Cantiga de Amor de Nuno Fernandes 
Torneol $^{4}$, que foi adaptada e interpretada na canção Love Song lançada em 1991 no álbum V da banda brasileira de rock Legião Urbana.

${ }^{5}$ Pois naci nunca vi Amor

e ouço del sempre falar;

pero sei que me quer matar,

mais rogarei a mia senhor:

que me mostr'aquel matador,

ou que m'ampare del melhor.

Pero nunca lh'eu fige rem

por que m'el haja de matar, mais quer'eu mia senhor rogar,

polo gram med'em que me tem:

que me mostr'aquel matador, ou que m'ampare del melhor!

Nunca me lh'eu ampararei, se m'ela del nom amaparar; mais quer'eu mia senhor rogar, polo gram medo que del hei: que mi amostr'aquel matador, ou que mi ampare del melhor.

E pois Amor há sobre mi de me matar tam gram poder e eu non'o posso ver, rogarei mia senhor assi: que mi amostr'aquel matador ou que m'ampare del melhor.

A métrica dessa Cantiga de Amor ratifica as colocações discutidas anteriormente a respeito da estrutura rítmica presente em Sonhei-te, já que como Moisés (2013) discute e notase na cantiga de Torneal, a voz lírica do texto vai ganhando ares emocionais ao modo em que vai sendo cantada, tentando exprimir a plangência do sentimento que consome esse ser, em repetições viciosas, que apenas mudam o grau de lamento e aumentam até o fim. Então ao

\section{${ }^{5}$ Glossário:}

Del: dele

Pero nunca lh'eu fige rem: ainda que eu nunca the tenha feito nada.

Del hei: do eu (pode ser traduzido por "eu tenho").
}

${ }^{4}$ Nuno Fernandes Torneol foi um trovador de origem desconhecida, apenas sabendo-se que poderia ter sido um cavaleiro ao serviço de um rico-homem de Castela. Cogita-se que este autor tenha se estabelecido na corte do rei Afonso X de Leão e Castela no século XIII. É-lhe reconhecida a autoria de vinte e duas composições, sendo treze cantigas de amor, extremamente convencionais, oito cantigas de amigo, de estrutura tradicional e uma cantiga de escárnio. Escrevia em português arcaico, ou mais especificamente no galaico-português. 
desenvolver esses recursos sonoros, o trovador conseguia articular e cativar melhor o seu público, deixando-o mais inteirado naquilo que pulsa o seu interior e no objeto de sua manifestação, tendo a melodia o papel circunstancial no fomento da personificação poética, que segundo os estudos de Bosi se dão pelo fato de que:

A melodia, ao imitar as inflexões da voz, exprime as queixas, os gritos de dor ou de alegria, as ameaças, os gemidos. Todos os signos vocais das paixões estão a seu cargo. Ela imita os acentos das línguas e os torneios que, em cada idioma, são afetados por certos movimentos da alma: não imita somente, fala. E a sua linguagem inarticulada, mas viva, ardente, apaixonada, tem cem vezes mais energia do que a própria palavra. (BOSI, 1977, p. 94-95).

E como a poesia trovadoresca teve socialmente o viés de uma linguagem oral, muitas de suas composições não possuíam títulos (como a cantiga de Tornoel), pois os trovadores não se preocupavam com definições que fixassem a ideia de suas cantigas, já que deixavam em aberto o campo das percepções e dos questionamentos por parte dos ouvintes. Ainda nessa perspectiva, Bosi expõe que:

\footnotetext{
A frase bem entoada nos dá, sinteticamente, o aspecto lógico da predicação e o estado sensível do canto. Conciliando, sob as espécies da voz, o conceito e quem o concebe, a melodia é um dos modos mais intensos e agudos da presença do Ser-aqui junto ao processo simbólico. Uniforme e pesada na afirmação pura, sinuosa na dúvida, abrupta na ordem, rompante ou ardida na pergunta, cariciosa no pedido ou sufocada, bifronte na ironia, espraiada na exclamação, a toada da linguagem afina as múltiplas situações emotivas e volitivas de quem fala. Como o andar, o portar-se do corpo, o aceno da cabeça, a mobilidade dos olhos. (BOSI, 1977, p. 98).
}

Nesse caso a não utilização de títulos em algumas cantigas trovadorescas não era apenas por uma questão estética, e sim, discursiva, já que ao impor títulos o sentido polissêmico das cantigas era perdido, e essa não era a proposta de intencionalidade que os trovadores buscavam.

\section{Conclusão}

Com base em todo o embasamento teórico que fora apresentado no decorrer deste trabalho, pode-se chegar à afirmação conclusiva de que, mediante a todos os aspectos estruturais, estéticos, estilísticos e discursivos analisados na construção do poema Sonhei-te 
da escritora fluminense Gilka Machado, foi constatada a presença de traços nítidos das características do Trovadorismo Português, por conta da distribuição narrativa dos versos, que munidos de uma voz apelativa, revela o desespero de um eu lírico perante a um sentimento mal resolvido, ratificado pelo fato de que, há a contextualização idealizada de um amor platônico, carregada de um lirismo visceral que sempre soa pessimista para com as premissas do amor em sua plenitude.

Segundo Cara (1989) o lirismo é uma maneira especial de recorte do mundo e de arranjo de linguagem. Podem existir temas mais líricos ou menos líricos, em função das expectativas de produção e leitura que, em cada tempo, criam predisposições em autores e leitores. Mas para o poeta e crítico moderno a poesia lírica concretizará, no modo como a linguagem do poema organiza os elementos sonoros, rítmicos e imagéticos. Por isso, Gilka Machado conseguiu incorporar dentro do rebuscamento estético do simbolismo, signos linguísticos que abriram o campo de percepção do leitor para uma consciência máxima das premissas apresentadas em suas produções, fazendo com que temáticas vistas desde o século XII até o século XX como profanas ou imorais, pudessem veicular ativamente entre o itinerário onírico de muitas pessoas, principalmente das mulheres da época.

Postura essa que é característica marcante na produção literária de autoria feminina, onde a mulher ao questionar aquilo que mexe com a sua percepção, torna o seu discurso compatível com os outros discursos circunvizinhos, dando a partir disso a possibilidade de sair do eixo singular e ter uma proporção plural, assim como acontece com a poesia de Gilka Machado.

Possibilitando também por meio da Literatura Comparada (LC), enxergar que os elementos dialógicos estão impregnados nesse processo de aproximação da poesia de Gilka Machado para com os traços do Trovadorismo, sendo, portanto esse dialogismo, a ressignificação da própria concepção poética de Gilka Machado, que apenas se deu por sua relação referencial com a Literatura Portuguesa. 
Referências

BATAILLE, Georges. O erotismo. Belo Horizonte: Autêntica editora, 2014.

BOSI, Alfredo. História concisa da LITERATURA BRASILEIRA. - 50. ed. - São Paulo: Cutrix, 2015.

BOSI, Alfredo. O ser e o tempo da poesia. São Paulo: Cultrix, Ed. da Universidade de São Paulo, 1977.

BRAGA, Teófilo. História da Literatura Portuguesa. Lisboa: Imprensa Nacional Casa da Moeda, 2005.

CANDIDO, A. O estudo analítico do poema. 3 ed. São Paulo: Humanitas Publicações FFLCH/USP, 1996.

CARA, de Almeida Salete. Poesia Lírica. São Paulo: Ed. Ática, 1989.

CARVALHAL, Tania Franco. Literatura comparada. 4 ed. São Paulo, Ática, 2006.

CROCE, Benetto. "A Literatura Comparada "In: COUTINHO \& CARVALHAL". (Org.). Literatura comparada: textos fundadores. Rio de Janeiro: Rocco, 1994. p. 60-64.

FENSKE, Elfi Kürten (pesquisa, seleção e organização). Gilka Machado - as múltiplas faces: o desejo, o amor, a angústia e a dor. Templo Cultural Delfos, maio/2013. (acessado em 08/01/2019).

FREUD, Sigmund. A Interpretação dos Sonhos partes I e II. São Paulo: Editora Escala, 2014.

JORGE, J. G de Araújo. Os Mais Belos Sonetos Que o Amor Inspirou. Brasil: Casa Vecchi, $1^{\mathrm{a}}$ ed. 1963.

MACHADO, Gilka. Poesias Completas. Rio de Janeiro: Cátedra; Brasília: INL, 1978.

MASSINI-CAGLIARI, Gladis. Cancioneiros medievais galego-portugueses. São Paulo: Martin Fontes, 2007.

MOISÉS, Massaud. A Literatura Portuguesa Através dos Textos. São Paulo: Cultrix, 2014. 
MOISÉS, Massaud. A Literatura Portuguesa. São Paulo: Cultrix, 2013.

MOISÉS, Massaud. Dicionário de termos literários. São Paulo: Cultrix, 2013.

NITRINI, Sandra. Literatura comparada (história, teoria e crítica). São Paulo, Edusp, 1997 (2 ed., 2000).

SILVA, Luiz Felipe Verçosa da. "A poesia como instrumento de substantivação e resistência do eu: uma análise do livro diVERsos". Anais do I Congresso Nacional de Estudos Lispectorianos. João Pessoa - PB: Editora da UFPB, 2018.

SPINA, Segismundo. A lírica trovadoresca. São Paulo: Edusp, 1990. 